\title{
Effect of Substituent Position on the Properties of Chalcone Isomer Single Crystals
}

\author{
R. Gandhimathi ${ }^{1}$, G. Vinitha ${ }^{2}$, R. Dhanasekaran ${ }^{1^{*}}$ \\ ${ }^{1}$ Crystal Growth Centre, Anna University, Chennai, India; ${ }^{2}$ Division of Physics, Vellore Institute of Technology, Chennai, India. \\ Email: *rdcgc@yahoo.com
}

Received June $24^{\text {th }}, 2013$; revised July $24^{\text {th }}, 2013$; accepted July $31^{\text {st }}, 2013$

Copyright (C) 2013 R. Gandhimathi et al. This is an open access article distributed under the Creative Commons Attribution License, which permits unrestricted use, distribution, and reproduction in any medium, provided the original work is properly cited.

\begin{abstract}
This paper summarizes the synthesis, growth and the effect of the position of the substituent in the thienyl ring and also the properties of the grown chalcone crystals, 2-CTP and 3-CTP. The formation of compound is confirmed by the recorded $\mathrm{H}^{1}$ NMR spectra. A FT-IR spectrum confirms the presence of all functional groups in both of the crystals. Single crystal XRD reports that even though these two compounds crystallize in monoclinic crystal system, 2-CTP has centrosymmetric $\mathrm{P} 2{ }_{1} / \mathrm{c}$ space group and $3-\mathrm{CTP}$ has non-centrosymmetric space group $\mathrm{P} 2_{1}$. Thermal properties of grown crystals analyzed by TG/DTA study explain that the 3-CTP compound is slightly more stable than 2-CTP. The transparency of these isomers in the vis-IR region has been studied. Second and third order nonlinear optical properties of 3-CTP and 2-CTP crystals have been investigated by powder SHG and Z-scan technique respectively.
\end{abstract}

Keywords: Solution Growth; Characterization; Chalcones; Nonlinear Optical Materials

\section{Introduction}

Chalcones are $\alpha, \beta$ unsaturated ketones. Chalcone molecules with a $\pi$-conjugated system provide a large charge transfer axis. The theory of charge transfer in molecules reveals the relationship between structure and NLO properties of organic compounds [1,2]. A series of chalcone materials have been reported for their very high second harmonic efficiency and third order nonlinear optical effects. Accordingly, we have chosen two chalcone materials for our investigation such as 3-(4-chlorophenyl)-1-(2-thienyl)-prop-2-en-1-one (2-CTP) and 3-(4chlorophenyl)-1-(3-thienyl)-prop-2-en-1-one (3-CTP). The interesting fact is that 2-CTP and 3-CTP compounds are positional isomers i.e. molecules with the same molecular formula have bonded together in different orders. On close observation it has been found that 2-CTP and 3CTP hold opposing views such as different molecular packing and optical properties. The arrangement of molecules in a crystal determines its physical and chemical properties. The 2-CTP and 3-CTP compounds have identical chemical compositions, but crystallize in different space groups where 2-CTP crystallizes in centro symmetric space group monoclinic $\mathrm{P} 2 / 1 / \mathrm{c}$ [3] and 3-CTP has noncentrosymmetric space group $\mathrm{P} 2{ }_{1}$. Many publica-

"Corresponding author. tions on chalcones are mostly focused on biological activities and second harmonic generation studies. Very recently chalcones have been studied for their third order nonlinear optical properties. Third order nonlinear refractive index $\left(\mathrm{n}_{2}\right)$, its sign, nonlinear absorption coefficient $(\beta)$ and third order nonlinear susceptibility $\left(\chi^{3}\right)$ of a thin nonlinear medium can be obtained from a linear relationship between the observed transmittance changes and the induced phase distortion by using Z-scan technique [4]. A strong delocalization of $\pi$-electrons in the prop2-en-1-one system of chalcone determines a very high molecular polarizability and hence the remarkable third order nonlinearities [5]. Taking this into cognizance, efforts have been taken to measure third order nonlinear refractive index, nonlinear absorption coefficient and nonlinear susceptibility of 2-CTP crystals by Z-scan technique. To show second order nonlinear optical effects, it is essential that the molecules are packed in such a way as to produce a non-vanishing electrical dipole moment. Substitution of prop2-en-1-one chain on 3-postion of thiophene ring influences noncentrosymmetric crystal packing in 3-CTP and the molecules exhibit non-zero $\beta$ values. Hence it is suitable for second harmonic generation. The main focus of this paper is to analyze the relationships between structure and nonlinear optical (NLO) properties of compounds in terms of influence of mo- 
lecular configuration on linear and NLO properties.

\section{Experiment}

\subsection{Synthesis}

Chalcones consist of two aromatic rings in trans-configurations separated by three carbons of which two are connected by double bond while the third is a carbonyl group. The general structure of chalcone [6] is<smiles>[Y][14CH2][14CH2][14C]([Y])=O</smiles>

The chalcone isomers 2-CTP and 3-CTP have been synthesized by Claisen Schmit condensation method [79]. However the precursors taken for these two compounds are different. These chalcones consist of a thiophene ring, prop2-en-1-one and a benzene ring. The positional isomerism arises due to the attachment of side chain (prop2-en-1-one functional group along with the benzene ring) at 2, 3 positions of thiophene ring. The molecular formula for these isomers is $\mathrm{C}_{13} \mathrm{H}_{9} \mathrm{ClSO}$.

\subsection{Determination of Solubility}

The solubility of 2-CTP and 3-CTP in acetone has been determined by the gravimetric method. A small amount of 2-CTP compound was dissolved in $20 \mathrm{ml}$ of acetone and it was allowed to stir for $2 \mathrm{hrs}$ at $30^{\circ} \mathrm{C}$. The stirring was then stopped to allow the undissolved material to settle down. From the clear solution, $10 \mathrm{ml}$ of sample was carefully taken and placed into a pre-weighed container. The solvent was allowed to evaporate at room temperature to determine the mass of the remaining material. Thus the solubility of 2-CTP in acetone at $30^{\circ} \mathrm{C}$ was determined. This process was repeated for various temperatures namely, $35^{\circ}, 40^{\circ}, 45^{\circ}$ and $50^{\circ} \mathrm{C}$ and the solubility process has been carried out for 3-CTP compound also. Solubility curves of 2-CTP and 3-CTP in acetone are shown in Figure 1. Both the compounds dissolve in acetone, however their solubility differs from each other. 2-CTP dissolves more than 3-CTP single crystals.

\subsection{Growth of 2-CTP and 3-CTP Single Crystals}

Chalcone family crystals were grown by low temperature solution growth method because these compounds dissolve well in organic solvents and easily grow from solution. $200 \mathrm{ml}$ of saturated solutions of 2-CTP and 3-CTP in acetone were prepared at $35^{\circ} \mathrm{C}$ and $40^{\circ} \mathrm{C}$ respectively and kept inside a constant temperature bath. The growth was initiated by slow evaporation of acetone, which leads to the formation of crystals within a period of seven days. The grown 2-CTP crystals by solvent evaporation tech- nique are shown in Figure 2(a) and 3-CTP crystals obtained by solvent evaporation method are shown in Figures 2(b) and (c). The colours of isomers are pale yellow.

\section{Results and Discussion}

\subsection{NMR Spectra}

$\mathrm{H}^{1}$-NMR spectra of 2-CTP and 3-CTP crystals show signals for nine protons and it indicates five different kinds of hydrogen environment present in the 3-CTP molecule. The recorded NMR spectra are shown in Figurs 3 and 4 respectively. The NMR spectrum of 2-CTP shows a multiplet at $7.18-7.20 \mathrm{ppm}$, which corresponds to a proton at 3-position of the thiophene ring. A multi-

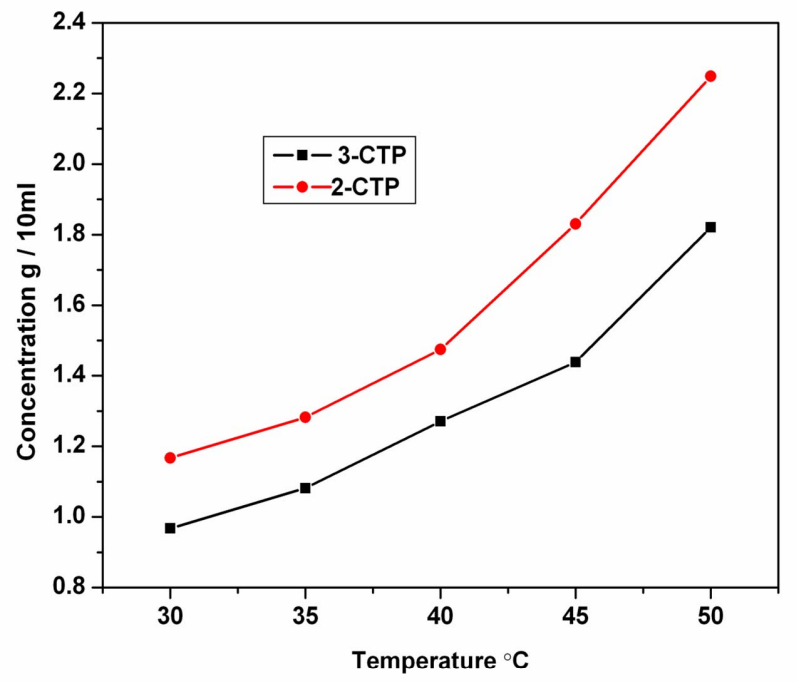

Figure 1. Solubility curves of 2-CTP and 3-CTP compounds in acetone.
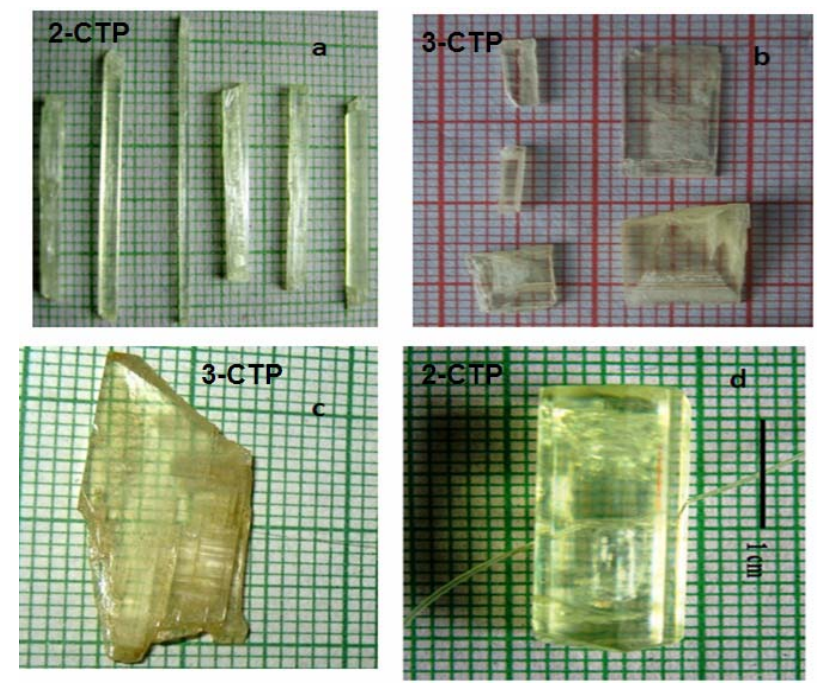

Figure 2. 2-CTP and 3-CTP single crystals grown by solvent evaporation and slow cooling techniques. 


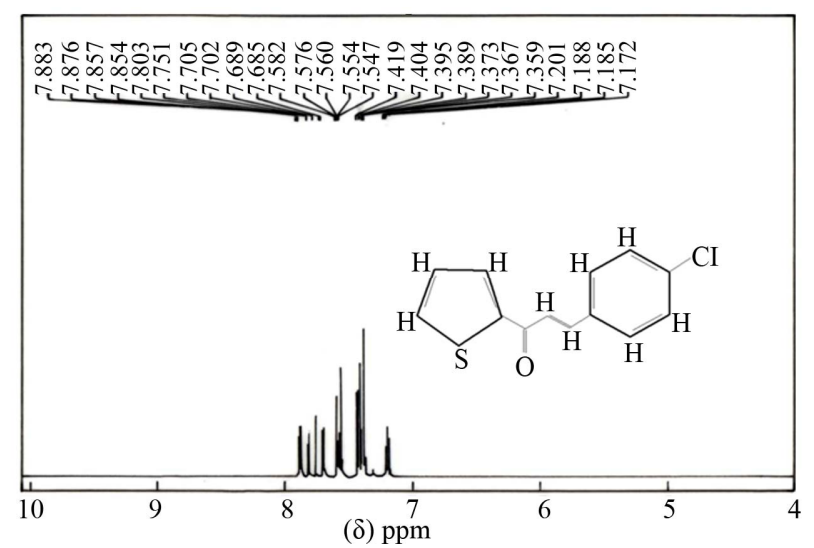

Figure 3. $\mathbf{H}^{1}$ NMR spectrum of 2-CTP.

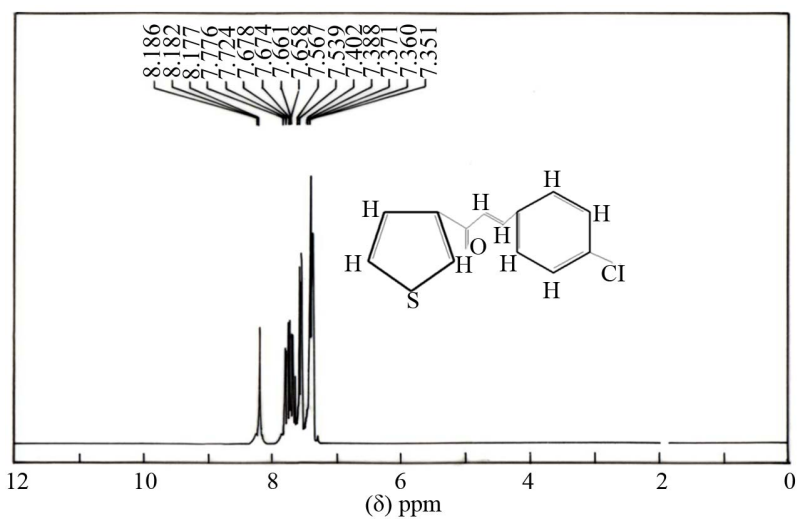

Figure 4. $\mathrm{H}^{1}$ NMR spectrum of 3-CTP.

plet which appears at $7.35-7.41 \mathrm{ppm}$ corresponds to two chalcone protons. The aromatic protons appear as a multiplet at $7.68-7.88 \mathrm{ppm}$. A doublet at $7.57 \mathrm{ppm}$ corresponds to $4^{\text {th }}$ and $5^{\text {th }}$ position protons of thiophene ring. The $\mathrm{H}^{1} \mathrm{NMR}$ spectrum of 3-CTP shows a multiplet at 8.19 - $8.18 \mathrm{ppm}$, which corresponds to a proton at 2-position of thiophene ring. A multiplet, which appears at 7.77 - $7.66 \mathrm{ppm}$ corresponds to two chalcone protons. The aromatic protons appear as a multiplet at $7.40-7.35$ $\mathrm{ppm}$. A doublet at $7.55 \mathrm{ppm}$ corresponds to 4 and $5^{\text {th }}$ position protons of thiophene ring. These peaks confirm the formation of the compounds $[10,11]$. The compound formation was confirmed by the recorded $\mathrm{H}^{1} \mathrm{NMR}$ spectra and they reveal the substitution to 2-position of thienyl ring in 2-CTP causing a downfield shift of approximately $0.9-1 \mathrm{ppm}$ from the substitution to 3-position of thienyl ring in 3-CTP. $\mathrm{H}^{1} \mathrm{NMR}$ peak assignments are tabulated in Table 1.

\subsection{FT-IR Studies}

The FT-IR absorption spectra of grown crystals recorded in mid-IR range $400 \mathrm{~cm}^{-1}-4000 \mathrm{~cm}^{-1}$ is shown in Figure 5. The difference in strength of the absorbance of peaks shows the existence of bonds with different dipole moment in the 2-CTP and 3-CTP molecules. The shift in frequency shows the different energy requirement for the molecule for absorbing infrared radiation. The peak assignments of functional groups are tabulated in Table 2. It has been noted that these two compounds differ significantly in the finger print region. C-C stretching of thiophene to prop2-en-1-one side chain has been observed at around $1195 \mathrm{~cm}^{-1}$. It is a doublet in the 3-CTP material, where as in the 2-CTP spectrum it appears as a single peak.

Table 1. H $^{1}$ NMR chemical shift assignments.

\begin{tabular}{ccc}
\hline 2-CTP & 3-CTP & $\begin{array}{c}\text { Chemical shift } \\
\text { assignments }\end{array}$ \\
\hline $7.18-7.20(\mathrm{~m}, 1 \mathrm{H})$ & $8.19-8.18(\mathrm{~m}, 1 \mathrm{H})$ & $3,2-\mathrm{H}$ of thienyl \\
$7.35-7.41(\mathrm{~m}, 2 \mathrm{H})$ & $7.77-7.66(\mathrm{~m}, 2 \mathrm{H})$ & prope2-en-1-one \\
$7.57(\mathrm{~d}, 2 \mathrm{H})$ & $7.55(\mathrm{~d}, 2 \mathrm{H})$ & $4,5-\mathrm{H}$ of thienyl \\
$7.68-7.88(\mathrm{~m}, 4 \mathrm{H})$ & $7.40-7.35(\mathrm{~m}, 4 \mathrm{H})$ & aromatic \\
\hline
\end{tabular}

Table 2. Peak assignments.

\begin{tabular}{ccc}
\hline \multicolumn{2}{c}{ Wave number $\left.\mathbf{( c m}^{-1}\right)$} & Peak assignments \\
\hline 2-CTP & 3-CTP & Aromatic weak C-H stretching \\
\hline 3155 & 3160 & C-H stretch C is part of aliphatic \\
3076 & 3083 & C=O stretching \\
1641 & 1652 & C=C stretching of aliphatic chain \\
1584 & 1565 & C-C stretching \\
1195 & 1190 & C-H out-of-plane bend \\
1067 & 1068 & Aryl halides C-Cl stretching \\
859 & 860 & 1,4,disubstituted benzene \\
813 & 806 & C-H deformation \\
769 & 758 & C-S stretching, weak \\
733 & 720 & \\
\hline
\end{tabular}

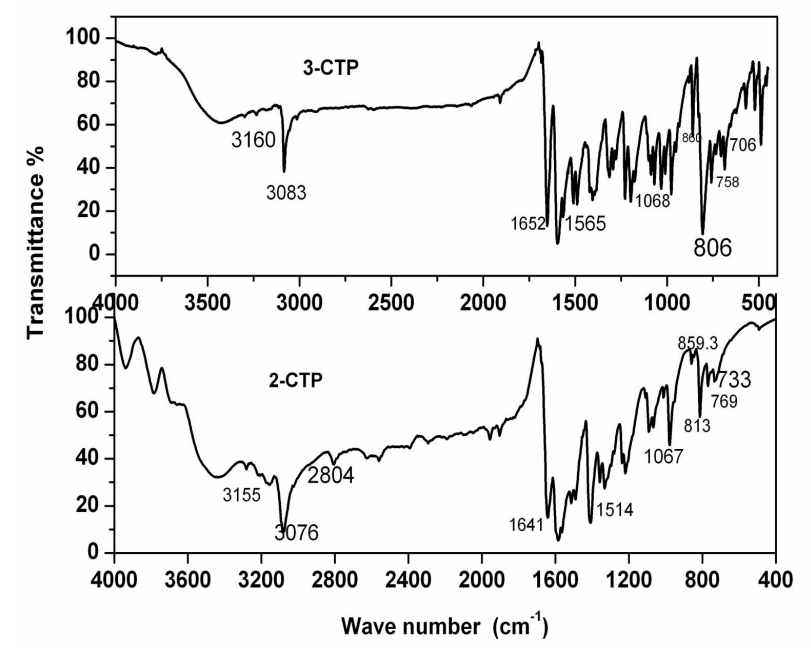

Figure 5. FT-IR spectra of 2-CTP and 3-CTP single crystals. 


\subsection{Powder XRD Spectra of Chalcone Isomers}

$\mathrm{X}$-ray powder diffraction analysis was carried out using a SEIFERT JSO-DEBYE FLEX 2002 Powder X-ray diffractometer with $\mathrm{CuK} \alpha$ radiation of wavelength (1.541 $\AA$ ) in the scanning range from $10^{\circ}$ to $50^{\circ}$. The obtained XRD peaks were indexed by using Winpltor software package. The XRD patterns of powdered 2-CTP and 3-CTP crystals are shown in Figure 6. From the recorded X-ray diffraction pattern, it was found that the peak corresponding to (105) has a maximum count of 400 and it is the more intense diffraction peak in the case of 3-CTP crystals whereas in 2-CTP, (114) peak is the strongest. Due to the changes in symmetry of 2-CTP and 3-CTP molecules, these isomers show different XRD patterns.

\subsection{Single Crystal X-Ray Diffraction}

Single crystal XRD analysis has been performed using Enraf Nonius CAD4-MV31 single crystal X-ray diffractometer. From the results it is known that the grown crystals belong to monoclinic crystal system. However, 2-CTP crystals crystallize with centrosymmetric space group $\mathrm{P} 2{ }_{1} / \mathrm{c}$ and the incorporation of characteristic chalcone chain at 3-position of thiophene in 3-CTP makes the material to crystallize with noncentrosymmetric space group $\mathrm{P} 2{ }_{1}$. The evaluated lattice parameter values are tabulated in Table 3 .

\subsection{Thermal Analysis}

To study the thermal stability of grown 2-CTP and 3CTP crystals, the DTA/TGA analyses were carried out in the temperature range of $0^{\circ} \mathrm{C}$ and $600^{\circ} \mathrm{C}$ in the nitrogen atmosphere with a heating rate of $10^{\circ} \mathrm{C} / \mathrm{min}$ using
Netzsch STA 409 CD thermal analyzer. The DTA/TGA curves of 2-CTP and 3-CTP were shown in Figure 7. In the thermogram, DTA curves of the samples show two endothermic peaks. The first endothermic peaks correspond to the melting points of 2-CTP and 3-CTP crystals which were found at $130^{\circ} \mathrm{C}$ and $125^{\circ} \mathrm{C}$ respectively. The second endothermic peak in the DTA trace of 2-CTP indicates the boiling point as $306^{\circ} \mathrm{C}$ whereas in the DTA of 3-CTP, the boiling point is observed at $340^{\circ} \mathrm{C}$. TGA curves of both the samples show decomposition in a single stage and before the melting point no weight loss is observed. It has been found that 3-CTP crystal is slightly stable than 2-CTP crystal. However TGA curves of isomers show the full degradation after $350^{\circ} \mathrm{C}$.

\subsection{Vis-IR Spectra}

The optical absorption spectra of both the samples of 2-CTP and 3-CTP were recorded using CARY 5E UVVIS-NIR spectrophotometer. The visible-IR spectra of the samples were shown in Figure 8. The Vis-IR spectra of the 2-CTP and 3-CTP crystals show the transparency around $50 \%$ and $40 \%$ in the visible IR region respectively. Their cutoff values are almost the same and the maximum absorbance is assigned to $n-\pi *$ transition. Only $n-\pi *$ electronic transition is possible since the $C=O$ group of chalcones absorb UV light and promote excitation of electrons from one of the unshared pair $\mathrm{n}$ (from non bonding orbital) to anti bonding $\pi^{*}$ orbital in the molecules [12].

\subsection{Nonlinear Optical Studies}

The relative third order nonlinear effects were studied

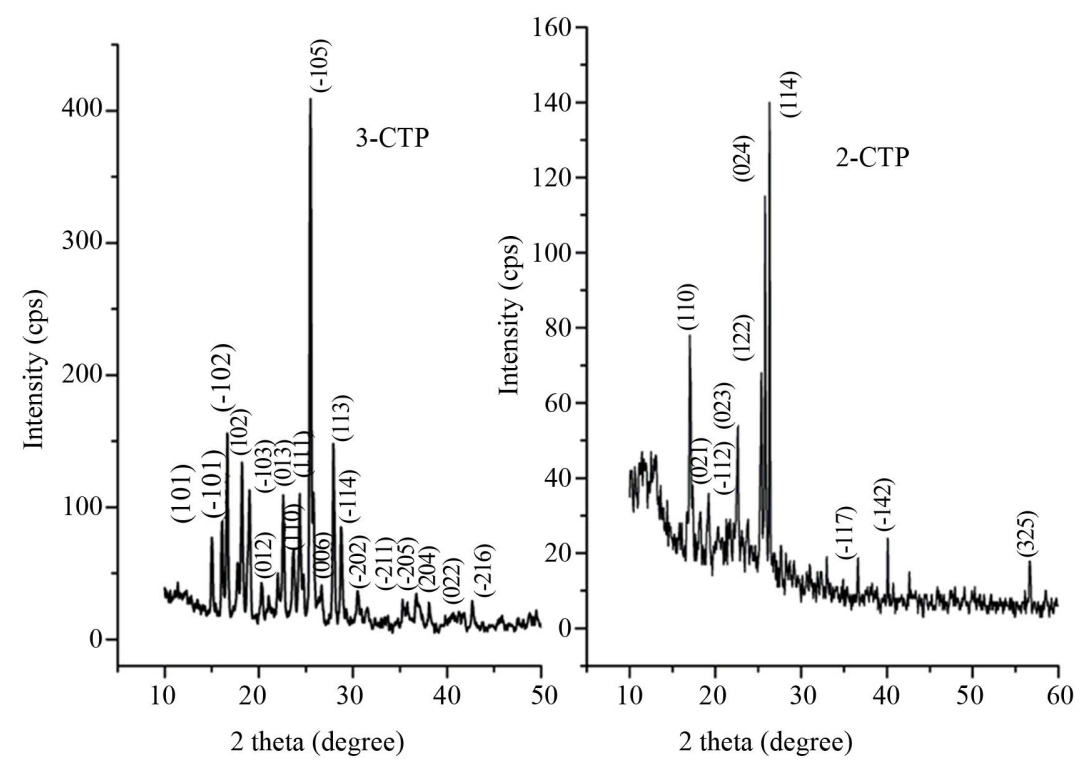

Figure 6. Powder XRD patterns of 3-CTP and 2-CTP crystals. 


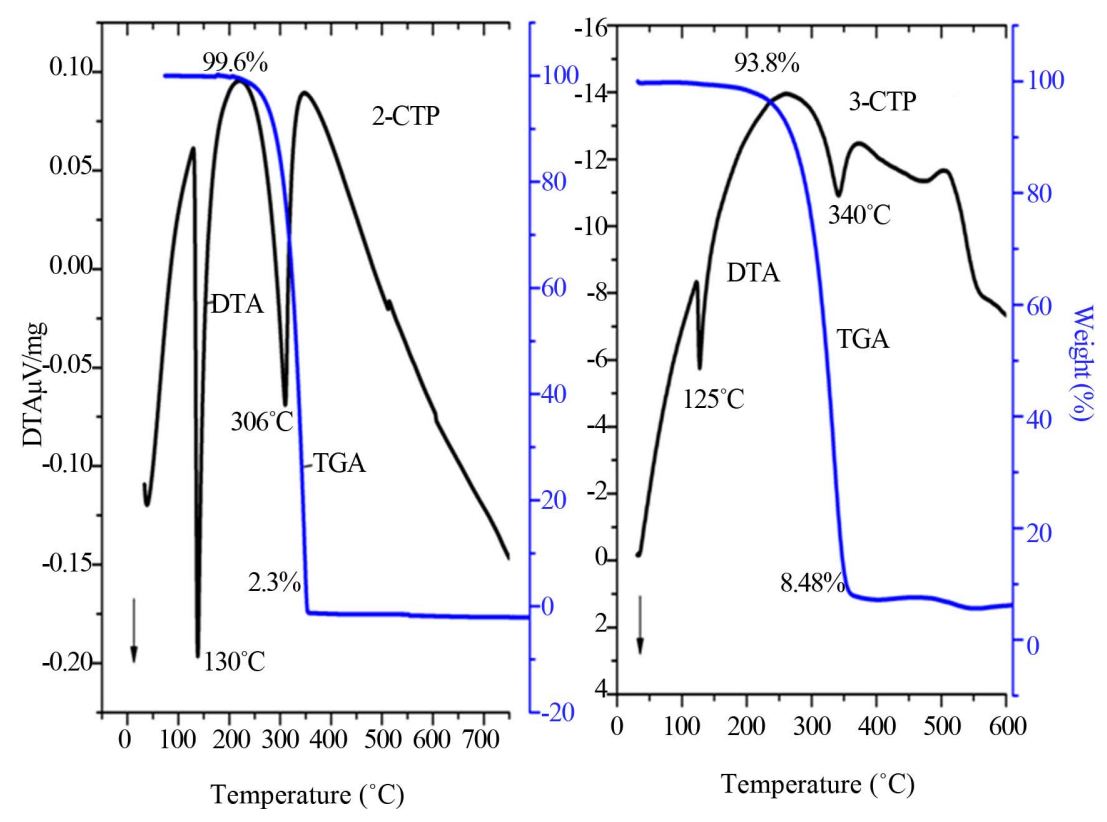

Figure 7. TG/DTA analyses of 2-CTP and 3-CTP single crystals.

Table 3. Lattice parameter values of 2-CTP and 3-CTP single crystals.

\begin{tabular}{ccc}
\hline Lattice parameters & 2-CTP & 3-CTP \\
\hline $\mathrm{a}(\AA)$ & 5.99 & 5.95 \\
$\mathrm{~b}(\AA)$ & 10.10 & 4.86 \\
$\mathrm{c}(\AA)$ & 18.97 & 20.09 \\
$\beta$ & 93.98 & 95.99 \\
\hline
\end{tabular}

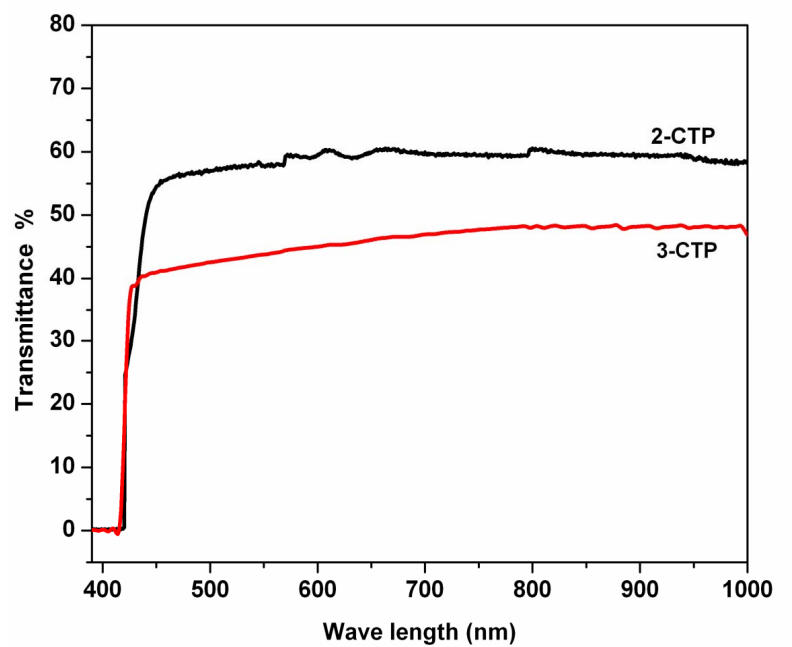

Figure 8. Vis-IR spectra of 2-CTP and 3-CTP single crystals.

using Z-Scan technique. Experiments were performed using a 532-nm diode-pumped Nd:YAG laser beam, which was focused by a $3.5 \mathrm{~cm}$ focal length lens. The laser beam waist $\omega_{0}$ at the focus is measured to be 15.84 $\mu \mathrm{m}$ and the Rayleigh length is $1.48 \mathrm{~mm}$. The optical nonlinearity of the 2-CTP solution with $60 \%$ transmission has been carried out by using $\mathrm{z}$ scan technique. The sign and magnitude of third-order refractive nonlinearities were calculated from closed aperture data. The closed aperture Z-scan trace of the 2-CTP exhibited a negative (defocusing) nonlinearity and large nonlinear refractive index of the order of $10^{-8} \mathrm{~cm}^{2} / \mathrm{W}$. The nonlinearity is of thermal origin. In chalcones, third order nonlinearity varies according to the distribution of $\pi$-electron density in the molecules [3]. The hetero cyclic 2-thienyl group and $\alpha, \beta$ unsaturated prop2-en-1-one at the centre of 2-CTP molecule have an effect of high electron donating and electron withdrawing property respectively. The chloro group attached at the other end of the 2-CTP molecules act as an electron acceptor. Hence the 2-CTP molecules possess donor-acceptor-acceptor type structure.

The open aperture curve of 2-CTP was shown in Figure 9(a). From the open-aperture $\mathrm{Z}$-scan data, the magnitude of intensity-dependent nonlinear absorption was derived, which exhibited a maximum transmittance at the focus $(z=0)$ that results off an induced negative nonlinear absorption effect due to the passage of laser light through prepared 2-CTP solution. Two-photon absorption coefficient of 2-CTP was calculated from the open aperture data. Pure nonlinear refractive index is obtained by dividing the closed aperture transmittance values by the corresponding open aperture scans [13]. The ratio of open aperture and closed aperture transmittance is shown in Figure 9(b), which gives pure nonlinear refractive 
index $n_{2}$ of 2-CTP. The third-order nonlinear optical susceptibility $\chi^{(3)}$ was calculated using the real and imaginary parts of third order nonlinear optical susceptibility $\chi^{(3)}$ according to the following relations

$$
\begin{gathered}
\operatorname{Re} \chi^{(3)}(\text { esu })=10^{-4} \frac{\varepsilon_{0} c^{2} n_{0}^{2} n_{2}}{\pi}\left(\frac{\mathrm{cm}^{2}}{W}\right) \\
\operatorname{Im} \chi^{(3)}(e s u)=10^{-2} \frac{\varepsilon_{0} c^{2} n_{0}^{2} n_{2}}{4 \pi^{2}} \lambda \beta\left(\frac{\mathrm{cm}}{W}\right) \\
\chi^{(3)}=\sqrt{\operatorname{Re} \chi^{(3)^{2}}+\operatorname{Im} \chi^{(3)^{2}}}
\end{gathered}
$$

$\chi^{(3)}$ for 2-CTP was found to be $4.86 \times 10^{-6}$ e.s.u. The measured susceptibility $\chi^{(3)}$ is relatively large when compared to other chalcone's values reported which is in the order of $10^{-13}$ e.s.u [14].

\subsection{Birefringence Measurement on 3-CTP}

The interference of emergent ordinary and extraordinary waves from a briefringent crystal, after passing through an analyzer oriented at $45^{\circ}$ generates intensity distribution patterns. The observed fringes and their spacing depend on the orientation of the crystallographic axes $(\mathrm{x}, \mathrm{y}$, z) and the different parameters characterizing the birefringence [15]. Initially a beam of light from the He-Ne laser source was passed through a well-polished 3-CTP single crystal of $0.5 \mathrm{~mm}$ thickness (not along the optic axis). Upon entering 3-CTP crystal it splits into two plane polarized light components (ordinary and extraordinary rays) which travel with different velocities and maintain a constant phase difference with respect to each other. The vibration plane of the polarized lights should be at $45^{\circ}$ to the plane containing optic axis of the crystal. This is achieved by rotating the crystal until the intensities of the ordinary and the extraordinary rays are same.
Hence the emergent rays from a coherent source polarized at right angles to each other. After travelling through the crystal, the light was allowed to enter the analyzer. When these two rays pass through the analyzer, they superimpose to produce constructive or destructive interference patterns depending upon the path difference existing between them. The interference pattern (bright and dark fringes) was captured on the screen which was placed behind the analyzer. The interference patterns obtained are shown in Figures 10(a) and (b) exhibiting uniform spacing between the fringes, which is an indication of no defects and refractive index being identical throughout the orientation. Figures 10(c) and (d) show distortions in the fringe pattern which is attributed to the patterns formed by the defective portion of the crystals. A power meter was used to detect the light transmitted through the analyzer. The birefringence $(\Delta n)$ can be calculated using the relation [16].

$$
\Delta n=\frac{\lambda}{\pi d} \sin ^{-1} \sqrt{\frac{I}{I_{o}}}
$$

where $I$ and $I_{o}$ are the intensities of light reaching the detector with and without sample, respectively and $\mathrm{d}$ is the thickness of the sample. The birefringent value is calculated for 3-CTP single crystals is 0.024 at a particular wavelength of $632.8 \mathrm{~nm}$.

\subsection{SHG Study on 3-CTP}

To find the SHG conversion efficiency of the NLO crystals, the powder technique developed by Kurtz and Perry [17] were used. However, the powder SHG observed for any given sample may vary with a number of parameters, including laser wavelength, particle size, temperature, crystallization solvent and sample preparation. In our present investigation, the powdered sample of 3-CTP

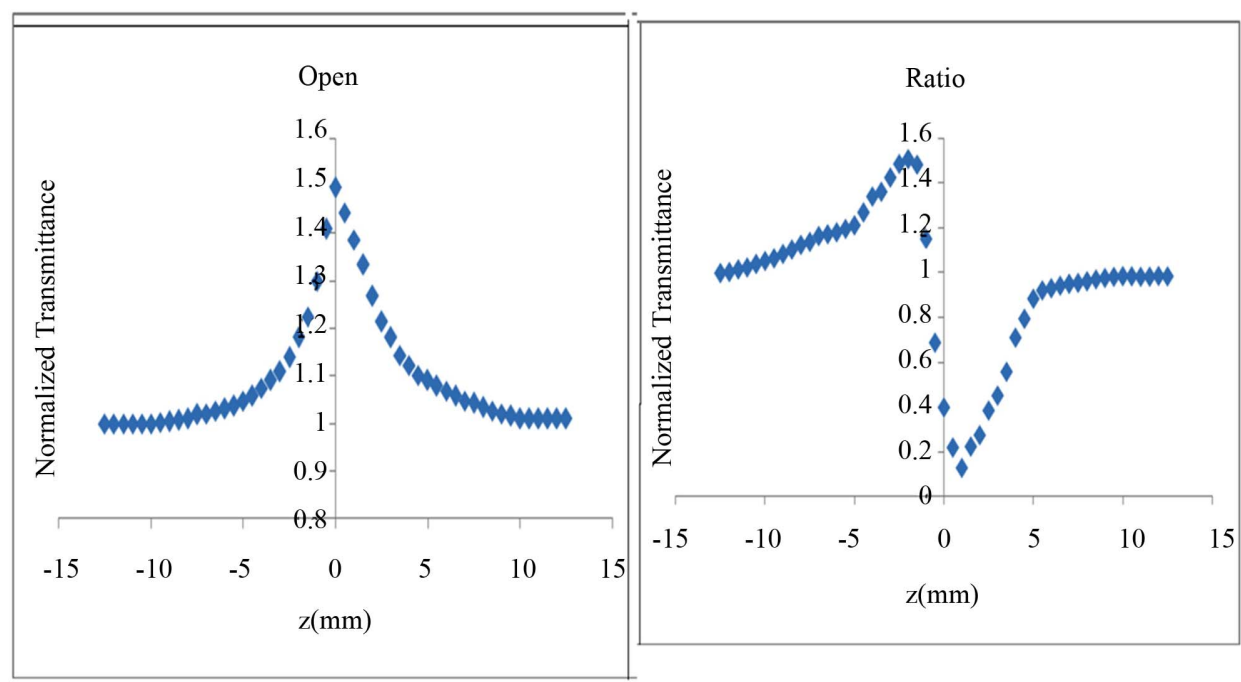

Figure 9. (a) and (b) open aperture and ratio of closed and open aperture curves. 

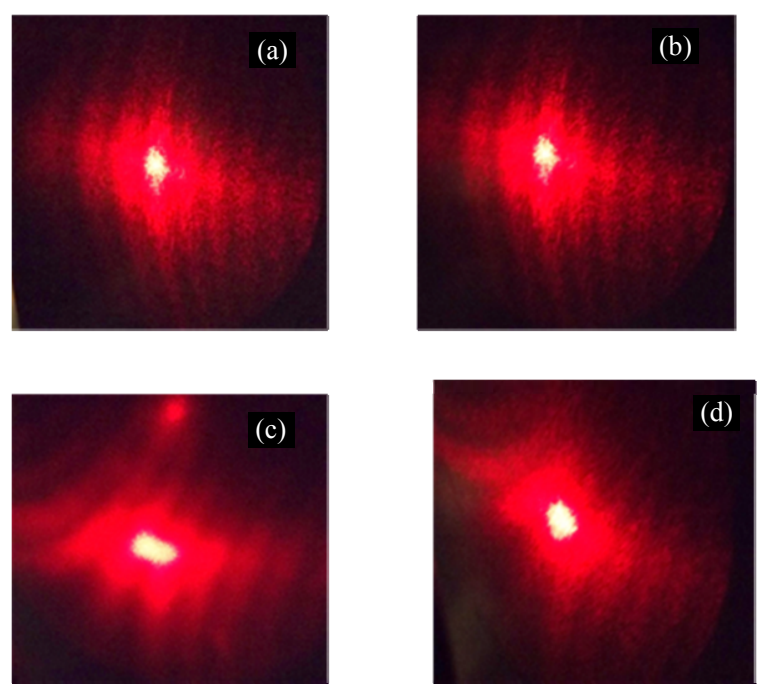

Figure 10. Interference fringe pattern of 3-CTP single crystals.

was packed in a triangular cuvette and it was subjected to the irradiation of laser from Nd:YAG with wavelength of $1064 \mathrm{~nm}$. A laser beam with the 8 nanosecond pulses and the energy of $300 \mathrm{~mJ}$ (each laser pulse) has been allowed to transmit through the cuvette. A Hamamatsu R-928 photomultiplier tube was used for the detection of emergent signal. SHG-measurement directly displayed on the oscilloscope screen was recorded (peak to peak volts). The same experimental procedure was repeated five times and an average of these five voltages gives the signal height. For the KDP crystal powdered with identical size of sample was subjected to same experimental procedure and the SHG efficiency of the 3-CTP has been found to be 2.7 times than that of reference material KDP. The comparison of SHG efficiency of 3-CTP material with KDP is shown in Figure 11. Nonlinear optical properties of chalcone isomers were tabulated in Table 4.

\section{Conclusion}

Chalcone isomers 2-CTP and 3-CTP were synthesized and grown as single crystals by solution growth technique. $\mathrm{H}^{1} \mathrm{NMR}$ and FT-IR studies confirm the formation and presence of all functional groups in the compounds. The single crystal XRD studies confirm the monoclinic crystal system of the synthesized materials and the results indicate that the position of the chalcone chain has remarkable impacts on molecular packing of crystallization. The Vis-IR studies prove the good transparency of the material in visible absorption and indicate the possibility for utilization in nonlinear optical devices. Thus the difference in molecular structure alters the electronic properties of the molecules and leads to different order in nonlinear optical effects in organic compounds. Enhanced $\pi$-electron density through the prop2-en-1-one

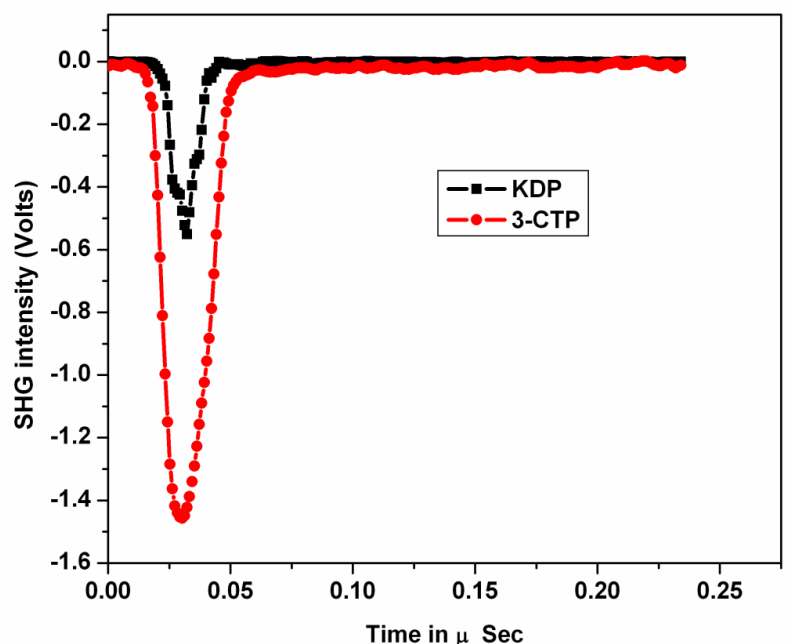

Figure 11. Comparison of SHG efficiency of 3-CTP with KDP.

Table 4. Nonlinear optical properties of chalcones.

\begin{tabular}{lcc}
\hline \multicolumn{1}{c}{ Materials } & 2-CTP & 3-CTP \\
\hline $\begin{array}{l}\text { Properties } \\
\text { Brewster angle method }\end{array}$ & 1.572 & 1.60 \\
2. Second harmonic generation & - & $\begin{array}{c}\text { 2.7 times better } \\
\text { than KDP }\end{array}$ \\
$\begin{array}{l}\text { 3. Third order nonlinear } \\
\text { optical effects } \\
\text { a) nonlinear refractive } \\
\text { index } n_{2}(\mathrm{~cm} / \mathrm{W}) \\
\text { b) nonlinear absorption } \\
\begin{array}{l}\text { coefficient } \beta(\mathrm{cm} / \mathrm{W}) \\
\text { c) nonlinear }\end{array}\end{array}$ & $1.13 \times 10^{-8}$ & \\
Susceptibility $\chi^{(3)}(\mathrm{esu})$ & $2.46 \times 10^{-3}$ & \\
\hline
\end{tabular}

conjugated bridge increases the third order nonlinear response of the 2-CTP compound. Noncentrosymmetric space group, good transparency in visible region, moderate birefringent value compared to other organic materials and high SHG efficiency of 3-CTP crystals are factors that confirm that this material is a prospective material for frequency conversion applications.

\section{REFERENCES}

[1] D. S. Chemla, J. L. Oudar and J. Jerphagnon, "Origin of the Second-Order Optical Susceptibilities of Crystalline Substituted Benzene," Physical Review B, Vol. 12, No. 10, 1975, pp. 4534-4546. http://dx.doi.org/10.1103/PhysRevB.12.4534

[2] J. Zyss, "Hyperpolarizabilities of Substituted Conjugated Molecules. III. Study of a Family of Donor-Acceptor Disubstituted Phenyl-Polyenes," Chemical Physics, Vol. 71, No. 2, 1979, pp. 909-917.

[3] H.-K. Fun, S. R. Jebas, P. S. Patil and M. Dharmaprakash, "(E)-3-(4-Chlorophenyl)-1-(2-thienyl)prop-2-en-1-oneActa. 
Cryst," Acta Crystallographica, Vol. E64, No. 1, 2008, pp. 1592-1593.

http://dx.doi.org/10.1107/S1600536808022782

[4] M. Sheik-Bahae, A. A. Said, T.-H. Wei, D. J. Hagan and E. W. Van Stryland, "Sensitive Measurement of Optical Nonlinearities Using a Single Beam," IEEE LEOS News Letter, Vol. 21, No. 1, 2007, pp. 17-26.

[5] A. J. Kiran, K. Chandrasekharan, B. Kallurya and H. D. Shashikala, "Chalcone Possible New materials for Third Order Nonlinear Optics,” In: S. V. Arnold, Ed., Chemical Physics Research Trends, Nova Science Publishers Inc., New York, 2007, pp. 247-257.

[6] T. Uchida, K. Kozawa, Y. Kimurab and Y. Gotob, "Structural Study on Chalcone Derivatives," Synthetic Metals, Vol. 71, No. 1-3, 1995, pp. 1705-1706. http://dx.doi.org/10.1016/0379-6779(94)03013-V

[7] R. Laliberte, J. Manson, H. Warwick and G. Medawar, "Synthesis of New Chalcone Analogues and Derivatives," Canadian Journal of Chemistry, Vol. 46, No. 11, 1968, pp. 1952-1956. http://dx.doi.org/10.1139/v68-324

[8] M. A. Hassan, S. Batterjee and L. A. Taib, "Novel Synthesis of 1H-Inden-1-Ones and Thienylpropenones in Aqueous Medium," Journal of the Chinese Chemical Society, Vol. 53, No. 4, 2006, pp. 939-944.

[9] Y. P. He, G. B. Su, G. M. Yiu, X. J. Huang and R. H. Jang, "Growth and Characterization of a New Organic Nonlinear Optical Crystal: 1-(3-Thienyl)-3-(4-chiorophenyl)propene-1-one," Journal of Crystal Growth, Vol. 141, No. 3-4, 1994, pp. 389-392. http://dx.doi.org/10.1016/0022-0248(94)90243-7

[10] S. A. Basaif, T. R. Sobahi, A. Kh. Khalil and M. A. Hassan, "Stereoselective Crossed-Aldol Condesation of Hetarylmethyl Ketones with Aromatic Aldehydes in Water: Synthesis of (2E)-3-Aryl-1-hetarylprop-2-en-1-ones," Bul- letin of the Korean Chemical Society, Vol. 26, No. 11, 2005, pp. 1677-168.

[11] Y. Budak, M. B. Gürdere, M. Keçeci and M. Ceylan, "Preparation of Diethyl Malonate Adducts from Chalcone Analogs Containing a Thienyl Ring," Bulletin of the Chemical Society of Ethiopia, Vol. 24, No. 1, 2010, pp. 8591.

[12] V. Crasta, V. Ravindrachary, R. F. Bhajantri and R. Gonsalves, "Growth and Characterization of an Organic NLO Crystal: 1-(4-Methylphenyl)-3-(4-ethoxyphenyl)-2-propen-1one," Journal of Crystal Growth, Vol. 267, No. 1-2, 2004, pp. 129-133. http://dx.doi.org/10.1016/j.jcrysgro.2004.03.037

[13] S. B. Mansoor, A. A. Said, T. H. Wei, D. J. Hagan and E. W. Van Stryland, "Sensitive Measurement of Optical Nonlinearities Using a Single Beam," IEEE Journal of Quantum Electronics, Vol. 26, No. 4, 1990, pp. 760-769.

[14] H. J. Ravindra, A. J. Kiran, K. Chandraskharan, H. D. Shashikala and S. M. Dharmaprakash, "Third Order Nonlinear Optical Properties and Optical Limiting in Donor/Acceptor Substituted 4'-Methoxy Chalcone Derivatives," Journal of Applied Physics, Vol. B88, No. 1, 2007, pp. $105-110$. http://dx.doi.org/10.1007/s00340-007-2677-8

[15] F. A. Jenkins and H. E. White, "Fundamentals of Optics," 3rd Edition, MacGraw-Hill, New York, 1957.

[16] A. M. Nasr, "Determination of Refractive Index and Birefringence of Dye Doped Polycarbonate Films Prepared by Different Techniques," International Journal of Materials Sciences, Vol. 2, No. 1, 2007, pp. 103-109.

[17] S. K. Kurtz and T. T. Perry, "A Powder Technique for the Evaluation of Nonlinear Optical Materials," Journal of Applied Physics, Vol. 39, No. 8, 1968, pp. 3798-3813. http://dx.doi.org/10.1063/1.1656857 